\title{
Spontaneous disconnection of glaucoma tube shunt extenders.
}

\author{
Oseluese Dawodu \\ Ophthalmology Department, University of Benin Teaching Hospital, Benin City, Nigeria
}

Alex V. Levin

Wills Eye Institute, Thomas Jefferson University, Philadelphia, Pennsylvania

Follow this and additional works at: https://jdc.jefferson.edu/willsfp

Part of the Ophthalmology Commons

Let us know how access to this document benefits you

\section{Recommended Citation}

Dawodu, Oseluese and Levin, Alex V., "Spontaneous disconnection of glaucoma tube shunt extenders." (2010). Wills Eye Hospital Papers. Paper 6.

https://jdc.jefferson.edu/willsfp/6

This Article is brought to you for free and open access by the Jefferson Digital Commons. The Jefferson Digital Commons is a service of Thomas Jefferson University's Center for Teaching and Learning (CTL). The Commons is a showcase for Jefferson books and journals, peer-reviewed scholarly publications, unique historical collections from the University archives, and teaching tools. The Jefferson Digital Commons allows researchers and interested readers anywhere in the world to learn about and keep up to date with Jefferson scholarship. This article has been accepted for inclusion in Wills Eye Hospital Papers by an authorized administrator of the Jefferson Digital Commons. For more information, please contact: JeffersonDigitalCommons@jefferson.edu. 


\title{
As submitted to:
}

\author{
Journal of AAPOS
}

\section{And later published as:}

\section{"Spontaneous disconnection of glaucoma tube shunt Extenders"}

\section{Volume 14, Issue 4, August 2010, Pages 361-363 doi:10.1016/j.jaapos.2010.06.004}

Oseluese Dawodu, MBBS, FWACS, FICS ${ }^{\mathrm{a}}$ and Alex V. Levin, MD, MHSc ${ }^{\mathrm{b}}$ Author affiliations:

a/ Ophthalmology Department, University of Benin Teaching Hospital, Benin City, Nigeria

b/ Wills Eye Institute, Thomas Jefferson University, Philadelphia, Pennsylvania

Supported in part by Brandan's Eye Research Fund and the Foerderer Fund. Research was carried out at the Hospital for Sick Children, Toronto Canada. Presented in part as a poster at the 35th Annual Meeting of AAPOS, San Francisco, April 17-21, 2009.

Submitted February 5, 2010.

Revision accepted June 3, 2010.

Alex V. Levin, MD, MHSC, Wills Eye Institute, 840 Walnut Street, Philadelphia, PA 19107-5109 (email: alevin@willseye.org).

J AAPOS 2010;-:1-3. 
Glaucoma drainage implants frequently are used in children with severe forms of glaucoma, and tube extenders are sometimes required to compensate for ocular growth or when the intraocular portion of the tube is thought to be too short. We report 2 cases of spontaneous disconnection of a tube extender, occurring 8 months after insertion in one case and 3 years later in the other. In both cases the tube was removed and the patient treated with endoscopic diode laser photocoagulation.

When glaucoma drainage implants are used in children, ocular growth may cause the tube to retract from the anterior chamber.1,2 When this occurs, the distal opening of the tube is embedded in the corneal stroma or even outside of the anterior chamber. Tube extenders have been used successfully in such cases to reposition the intraocular portion of the tube. 3 Previously reported complications resulting from the use of tube extenders and shunts include migration into the anterior chamber after trauma,4 supra- choroidal effusion/hemorrhage, tube obstruction, implant extrusion/malposition, uveitis, corneal decompensation, retinal detachment, strabismus, cataract, hypotony, hyphema, and endophthalmitis.5,6 We report 2 patients treated for disconnection of a tube extender at the Hospital for Sick Children, Toronto.

\section{Case 1}

A 5-year-old boy with bilateral idiopathic iritis developed secondary glaucoma that required bilateral implantation of an adult, single-plate, nonguarded Molteno tube shunt (New World Medical, Inc, Rancho Cucamonga, CA). The plate was fixed to the sclera with two 6-0 nonabsorbable Ticron sutures (United States Surgical, Norwalk, CT). The tube tip was located approximately 3-4 mm inside the anterior chamber. Four years after initial placement, the tube retracted from the anterior chamber. The lumen was found to be buried within corneal stroma, and a bleb was no longer visible over the plate. The tube was trimmed to within $2 \mathrm{~mm}$ of the tube-plate junction and a tube extender (New World Medical, Inc) was attached.

The plate of the extender was fixed to sclera with two 10-0 nylon sutures. The portion distal to the junction was covered with a new partial-thickness scleral patch graft. Postoperatively the bleb over the Molteno plate was restored, and the glaucoma was satisfactorily controlled without additional medications. Best-corrected visual acuity remained at 20/20. On follow-up examination 3 years after insertion of the tube extender, IOP had increased to $32 \mathrm{~mm} \mathrm{Hg}$, and there was no longer a bleb over the left plate. Ultrasound biomicroscopy showed a cystic area anterior to the tube-plate junction with disconnection of the tube extender. Under general anesthesia, a self-sealing paracentesis was placed opposite the tube, and a 30-gauge cannula was used to inject fluorescein-labeled balanced salt solution into the tube opening. Most of the solution refluxed into the anterior chamber and some was seen within the cystic area overlying the junction of the tube extender and the Molteno tube. The discontinuity of the tube and tube extender was visible on ultrasound biomicroscopy imaging (Figure 1). Surgical exploration confirmed that the tube extender had disconnected from the original tube, and that fibrotic tissue had grown into the tube-plate junction as well as the lumen at each end of the tube. The tissue could not be successfully removed. The tube extender was 
removed and the eye was treated with endoscopic diode laser cycloablation.

\section{Case 2}

A 1-month-old boy with persistent ocular fetal vasculature was treated for bilateral cataracts with bilateral lensectomy and anterior vitrectomy. He developed aphakic glaucoma in the affected eye about 3 months after surgery and under went bilateral pediatric single-plate Molteno tube implantation 2 months later. During the next 18 months, the right tube progressively retracted within the anterior chamber until drainage was inadequate. A tube extender was inserted in the same fashion as described in Case 1. Eight months later the IOP was elevated, and there was no longer a satisfactory bleb over the plate. An attempt at flushing the tube, as described previously, failed to reestablish drainage. Surgical exploration revealed a disconnected tube extender with fibrosis that had become intercalated at the junction between the original tube and tube extender. The tube was removed; IOP was controlled temporarily by endoscopic diode laser ablation. Implantation of an Ahmed tube (New World Medical Inc) in another quadrant was later required for recurrent IOP elevation.

\section{Discussion}

Reported complications of the tube used for various glaucoma tube shunts include tube retraction, kinking, malpositioning, and exposure. 7 The earlier the glaucoma drainage tube is inserted in the life of a child, the greater the probability that tube extrusion may occur.7 To our knowledge, spontaneous disconnection of a functional tube extender has not been previously reported.

The need for close long-term surveillance of children with glaucoma drainage tube shunts cannot be overemphasized. Rapid growth of ocular structures in the very young, perhaps aggravated by buphthalmos associated with uncontrolled glaucoma, may change the relative distance between the base of the drainage plate and the desired end point for the tube within the anterior chamber. Approximately 50\% of the postpartum growth of the eye occurs in the first 2 years of life.8,9 The curve of eyeball growth shows rapid growth until 18 months, followed by a phase of slower growth.8 Computed tomography axial lengths of emmetropic globes measure $16.0 \pm 0.72 \mathrm{~mm}$ in newborns and $24.5 \pm 0.66$ $\mathrm{mm}$ in adults. 9 Although we did not measure axial length in our patients, we believe that in both cases the tube retracted at least in part as a result of ocular growth.

When a retracted tube prevents adequate drainage, tube extenders offer an option for reestablishing a functioning system. Advancing the plate requires invading the bleb and therefore is not as desirable. In aphakic or pseudophakic patients, the original tube could be placed in the sulcus or pars plana, but it is not clear that this would solve the problem of globe enlargement and disconnection.

A disconnected tube extender should be suspected when there is high IOP, no bleb over the plate, and a cyst that in the area of the junction between the primary tube and the proximal extender. Flushing with fluorescein-labeled balanced salt solution helped us 
distinguish the cyst (which promptly filled with the colored fluid) from the normal domeshaped "bubble" at the base of the tube extender. In our cases, the disconnection was too advanced to allow repair, and the patients required additional procedures for control of the glaucoma. It is possible that tube extender disconnection might be prevented by altering the implantation technique, either by covering the junction with a patch graft or by using glue, which might prevent this complication by discouraging fibrous ingrowth and allowing for tube extender replacement.

Literature Search

The authors conducted PubMed and Google searches by using the following keywords: glaucoma drainage devices complications, tube extender complications, and nontraumatic causes of tube migration.

\section{References}

1. Gignac D, Cussenot O, Deplus S, et al. Computation of eyeball growth by magnetic resonance imaging. Surgical Radiol Anat 1994;11:113-5.

2. Merrill KD, Suhr AW, Lim MC. Long-term success in the correction of exposed glaucoma drainage tubes with a tube extender. Am J Ophthalmol 2007;144:136-7.

3. Sarkisian SR, Netland PA. Tube extender for revision of glaucoma drainage implants. J Glaucoma 2007;16:637-9.

4. Sheets CW, Ramiattan TK, Smith MF, Dovie JW. Migration of glaucoma drainage device extender into anterior chamber after trauma. J Glaucoma 2006;15:559-61.

5. Munoz M, Tomey KF, Traverso C, et al. Clinical experience with Molteno implant in advanced infantile glaucoma. J Pediatr Ophthalmol Strabismus 1991;28:68-72.

6. Hill RA, Pirouzian A, Liaw L. Pathophysiology of and prophylaxis against late Ahmed glaucoma valve occlusion. Am J Ophthalmol 2000;129:608-12.

7. Pirouzian A, Demer JL. Clinical findings following Ahmed Glaucoma ValveÔ implantation in pediatric glaucoma. Clin Ophthalmol 2008;29: 123-7.

8. Bremond-Gignac $\mathrm{D}$, Cussenot $\mathrm{O}$, et al. Computation of eyeball growth by magnetic resonance imaging. Surg Radiol Anat 1994;16: 113-5.

9. Lee AJ, Saw SM, Gazzard G, et al. Intraocular pressure associations with refractive error and axial length in children. Br J Ophthalmol 2004;88:5-7. 


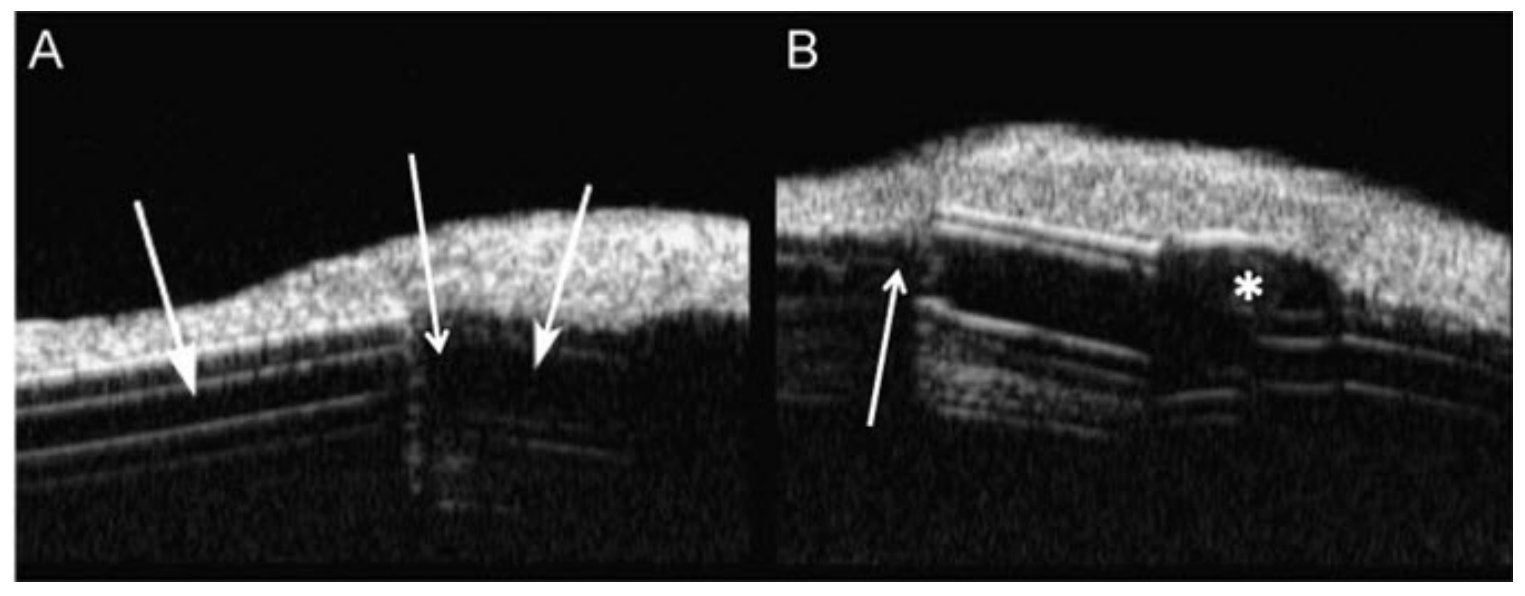

FIG. 1. Ultraound biomicroscope images of Case 1. A, Area of disconnection (center arrow) lies between original tube (left arrow) and tube extender (right arrow). B, Dome on the plate of the tube extender (asterisk) and area of disconnection (arrow). 